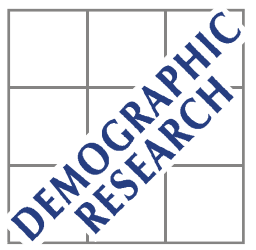

Demographic Research a free, expedited, online journal of peer-reviewed research and commentary in the population sciences published by the Max Planck Institute for Demographic Research Konrad-Zuse Str. 1, D-18057 Rostock · GERMANY www.demographic-research.org

DEMOGRAPHIC RESEARCH

VOLUME 25, ARTICLE 22, PAGES 695-722

PUBLISHED 20 OCTOBER 2011

http://www.demographic-research.org/Volumes/Vol25/22/

DOI: 10.4054/DemRes.2011.25.22

Research Article

Constructing a survey over time: Audio-visual feedback and theatre sketches in rural Mali

\title{
Véronique Hertrich
}

Marie Lesclingand

Martine Quaglia

\section{Amandine Stephan}

(C) 2011 Véronique Hertrich et al.

This open-access work is published under the terms of the Creative Commons Attribution NonCommercial License 2.0 Germany, which permits use, reproduction \& distribution in any medium for non-commercial purposes, provided the original author(s) and source are given credit. See http:// creativecommons.org/licenses/by-nc/2.0/del 


\section{Table of Contents}

1 Introduction $\quad 696$

2 Research over a 20-year period 699

2.1 The population 699

2.2 The observation system 700

2.3 Several surveys but a common feature: The same questions 701

$2.4 \quad$ Organization in the field 702

3 First stage: Obtaining the agreement of the population, a necessary formality 703

$4 \quad$ Highlighting the population's contribution to the survey: Basic $\begin{array}{ll}\text { feedback methods } & 704\end{array}$

$5 \quad$ The concept of a specific feedback project $\quad 706$

6 The audio-visual presentation: Objectives and implementation $\quad 707$

6.1 Capturing viewers' interest: Which ideas should take priority? 707

6.2 Making ourselves understood: How should the process be
formalized?

$\begin{array}{lll}6.3 & \text { Images and language } & 709\end{array}$

$\begin{array}{lll}7 & \text { Sketches in a village show } & 713\end{array}$

$8 \quad$ Communication, 'theatre' and 'cinema': Dissemination through $\quad 714$ spectacle?

$9 \quad$ Assessment and lessons learnt $\quad 715$

$\begin{array}{lll}9.1 & \text { Satisfied villagers and satisfied researchers } & 715\end{array}$

9.2 Public debate and knowledge transmission $\quad 716$

$\begin{array}{lll}9.3 & \text { Creating a shared space around the survey } & 717\end{array}$

$\begin{array}{lll}10 & \text { Acknowledgements } & 718\end{array}$

$\begin{array}{ll}\text { References } & 719\end{array}$ 


\title{
Constructing a survey over time: Audio-visual feedback and theatre sketches in rural Mali
}

\author{
Véronique Hertrich ${ }^{1}$ \\ Marie Lesclingand ${ }^{2}$ \\ Martine Quaglia ${ }^{3}$ \\ Amandine Stephan ${ }^{4}$
}

\begin{abstract}
Knowledge dissemination is an emerging issue in population studies, both in terms of ethics and data quality. The challenge is especially important in long term follow-up surveys and it requires methodological imagination when the population is illiterate. The paper presents the dissemination project developed in a demographic surveillance system implemented in rural Mali over the last 20 years. After basic experience of document transfer, the feedback strategy was developed through audiovisual shows and theatre sketches. The advantages and drawbacks of these media are discussed, in terms of scientific communication and the construction of dialogue with the target population.
\end{abstract}

\footnotetext{
${ }^{1}$ Institut national d'études démographiques (INED, Paris, France). E-mail: hertrich@ined.fr.

${ }^{2}$ Université de Nice (URMIS, IRD, UMR 205) and INED. E-mail: marie.lesclingand@unice.fr.

${ }^{3}$ Institut national d'études démographiques (INED, Paris, France). E-mail: quaglia@ined.fr.

${ }^{4}$ Institut national d'études démographiques (INED, Paris, France). E-mail: amandine.stephan@ined.fr.
} 


\section{Introduction}

Disseminating research results to a survey population, and more generally to a nonspecialized audience, is considered as an important, if not vital, process for most researchers and survey leaders. However, the principle is one thing - putting it into practice is another.

One main difficulty lies in our lack of competence in matters of communication. Finding attractive catch lines, simplifying our ideas without deforming them, using clear and forceful but non-specialized language, are not part of the academic skills taught at university. Popularizing and informing also mean detaching oneself from one's professional milieu and accepting challenges that are far removed from the researcher's usual scientific concerns (Bergier 2000; Bizeul 2008; Fassin and Bensa 2008; Flamand 2005; Kobelinsky 2008). Informing survey populations about our research findings calls for specific investments in time, skills, and resources, which are rarely taken into account in research projects and receive scant academic acknowledgement. In addition, knowledge dissemination tends to clash with end-of-project constraints, such as budget issues and the redeployment of the team in new projects with consequent scheduling problems. All of these factors cause those involved to scale down the operation - if not discard it altogether.

These common constraints are shared by all surveys, but additional ones occur when 1) research concerns a population with an oral culture and 2) the survey covers a long period of time.

(1) Addressing a population that scarcely uses the written word, if at all, obviously requires the mobilization of specific tools and a certain conceptual imagination. In such cases, handing over documents such as the 'summary report of findings' often used to summarize survey findings in western countries, hardly constitutes an efficient communication strategy. Moreover, being unfamiliar with a written language is more than a matter of paper and pencils or reading and writing. It also changes the way ideas are formalized and expressed in abstract terms, and does not correspond to the linear, continuous approach of the written word. It obliges us to review the way we represent information and our modes of communication.

(2) Carrying out a research project over time with a multi-round survey requires specific conditions for gathering data and developing relationships with respondents. This is the case for the demographic surveillance systems ${ }^{5}$ implemented in developing

\footnotetext{
${ }^{5}$ Also named Population Observatory, the Demographic Surveillance System (DSS) is a method implemented in a growing number of developing countries, especially in Africa, since the late 1980s, to address the problem of poor-quality data on demographic levels and trends due to the incompleteness of the civil registration system. For detailed methodological information and an overview of existing DSS, see Pison
} 
countries, which involve regular exhaustive surveys of local communities over periods of up to several decades or more. Unlike usual single-round surveys, where exchanges with the population are anonymous and take place just once, monitoring a population over time involves repeated personal exchanges. The same questions ${ }^{6}$ are asked every time, the respondents are known by name, and the team in the field (interviewer, interpreter, and survey leader) often remains unchanged over a number of years. The regular presence is favourable to interpersonal exchanges and enables discussion, disagreement, and even protest to emerge, which are more unusual in one-off surveys. Furthermore, the methodological choice of a demographic surveillance project usually entails a systematic and exhaustive survey of a delimited population, and high expectations in terms of data quality. From a scientific point of view these requirements for exhaustiveness and quality heighten the ethical challenge of information feedback to the population. Indeed, when fully informed and involved in the survey process, respondents are expected to be more willing to answer and to provide accurate information, enhancing the exhaustiveness and the reliability of the data (Mondain, Bologo, and Arduin 2010; Madhavan et al. 2007). In this sense, providing feedback and developing exchanges with the target population may be considered as an integral part of the follow-up process, in terms of both ethics and data quality.

While ethics has become an important issue in social sciences in recent decades, paradoxically the question of knowledge feedback has rarely been addressed until now. Even in anthropological research, a field especially concerned with the relationships between researchers and their informants, the topic has developed only since the 1990s, and initially in relation to data quality and epistemology, before being broached more recently in terms of ethics and reciprocity with respondents and local actors (Zonabend 1994; Bergier 2000; Fassin and Bensa 2008; Bosa 2008; Fassin 2008).

There is practically no discussion of the issue ${ }^{7}$ in the area of African population studies. Specific knowledge dissemination projects are probably implemented in various surveys, at least in small-scale studies, but they receive scant visibility in academic literature. When broached, the question of research feedbacks and relationships with the population remains an 'internal' affair, which we deal with as best we can behind the scenes. It is seen as a private matter, which, unlike other components of scientific practice, is not actually debated and therefore does not need to be reported. A literature review clearly shows that, except in the medical sciences,

(2005) and visit the Website from the Indepth network which covers most of the DSSs (http://www.indepthnetwork.org/).

${ }^{6}$ The range of questions varies between sites, but it usually includes questions on the births, deaths, marriages, and migrations which have occurred since the previous survey round.

${ }^{7}$ Except possibly in epidemiological and health surveys, a field where ethical rules are especially strict, at least concerning individual consent and access to medical results and treatment (e.g. for HIV/AIDS, mental health) (Bonnet 2003; MacLeod, Masilela, and Malomane 1998). 
dissemination is just beginning to emerge as an ethical and scientific issue, especially in demographic surveillance systems, as confirmed in recent publications (Madhavan et al. 2007; Mondain and Bologo 2009; Mondain, Bologo, and Arduin 2010). This article, based on specific field experience in Mali, is proposed as a contribution to this emerging debate in favour of effective scientific feedback and exchanges in Africa.

We will present the approach we have adopted in the population follow-up survey carried out in south-eastern Mali over two decades (Slam project ${ }^{8}$ ). Various operations of knowledge dissemination and exchange have been implemented in the course of this project, ranging from paper documents to more specialized media, including audiovisual presentations and theatre sketches created by the respondents themselves. These were 'home-made' tools we progressively developed and tested in order to improve the feedback process in a specific context, i.e., a rural population with little schooling and whose expectations are far removed from the usual end products of a research project. In describing our choices and methods we are also addressing the issues of communication (both successful dialogue and misunderstandings) and reciprocity in our exchanges with the survey population.

We will begin by broadly describing the field, including the population, the survey method, and the conditions of data collection. The following sections present the different approaches to information dissemination and exchanges with the population that we have tried out over the past 20 years. Details are given concerning the practical implementation of the project, since the material conditions can often be a major stumbling block. In the final section we will open the discussion on the presuppositions inherent to such a dissemination project.

Electronic files to be downloaded are available on the Journal website with the audio-visual presentation and a subtitled video of a theatre sketch, in both English and French Versions. ${ }^{9}$

\footnotetext{
${ }^{8}$ The research project "Slam-Suivi longitudinal au Mali / Longitudinal survey in Mali" is conducted at INED, under the scientific responsibility of Véronique Hertrich.

${ }^{9}$ The trilingual version (including in the local language) of the audio-visual presentation is available on a CD (Lesclingand and Hertrich 2007).
} 


\section{Research over a 20-year period}

\subsection{The population}

The population monitoring project was set up at the end of the 1980s in seven neighbouring villages, located in the Bwa (singular Boo) ethnic area of south-eastern Mali (Tominian Cercle), some $450 \mathrm{~km}$ from Bamako. The population lives off familybased agricultural production, mainly food crops. Fertility transition has not begun yet (eight children per women) and the natural growth rate is high (about 3\% per year). However, this natural growth is limited by migration, mainly internal or to neighbouring countries.

Like most populations in the region, the Bwa have a patrilineal organization with residency and filiation rules structured around the men. The village community is highly valued (Capron 1973, 1988), and this is expressed in the organization of households (domestic groups scattered across the village) and in the very frequent festivities (including one day of the week set aside for consuming millet beer and collective recreation). Social relations in the village are actively nurtured, thus building a sense of belonging and strong attachment of individuals to their village. This creates favourable conditions for a long-term data-gathering project: the villagers remember their neighbours well and usually know what has become of them, even if they left the village long ago.

The Bwa are also known for their independent spirit (Capron 1973, 1988), which is reflected, for instance, in their resistance to French colonialism (the 1916 revolt), but also more generally in their low participation in national integration structures (Diarra 2007). Other expressions of this are their low investment in schools and socioeconomic development programmes until the $1990 \mathrm{~s}$, as well as their resistance to Islam. ${ }^{10}$ The 1990s marked a turning point, both at the national level (arrival of democracy in 1991 and the ensuing process of decentralization) and at the local level, with a new commitment by the villages to development programmes, notably in schooling, through the establishment of community schools managed by the villagers themselves.

These societal features also reflect a community mode of functioning, with emphasis on collective debate and agreement. Any outside intervention must be presented and discussed in the public village space and cannot be implemented without prior consensus. A survey is no exception; as we shall see.

\footnotetext{
${ }^{10}$ A proportion of the villages converted to Christianity but traditional religions are widely practised. With the exception of a few individuals, Islam is not represented.
} 


\subsection{The observation system}

The observation system ${ }^{11}$ was set up in 1987-89, and we have carried out regular updates approximately every five years (1994-95, 1999-2000, 2004-05, and 2009-10). Data gathering is organized around two main quantitative surveys, a repeat survey and a life-event history survey, along with various secondary operations.

The repeat survey covers all the villages (4,200 inhabitants in 2009) and tracks what happens to the respondents from one census to the next. Each visit gives rise to a new census and the data are matched against those of previous rounds. Data from the national censuses are also integrated, with the cooperation of the Malian Institute of Statistics (Instat). In all, the database currently includes nine censuses spanning more than three decades (1976-2009): the four national ones (1976, 1987, 1998, 2009) and five local ones $(1988,1994,1999,2004,2009)$. The actual survey entails questioning families at each visit about what happened to the individuals who no longer appear in the new census (deaths, emigration, etc.) and, conversely, about the situation in the previous censuses of the individuals registered for the first time (children born since the last visit, immigrants, etc.).

The life event history survey covers two of the seven villages in the repeat survey (1,750 inhabitants in 2009) and is carried out on all residents (both sexes, all ages) as well as on emigrant men and never-married women of village lineages. The questionnaire records detailed marital, reproductive, migratory, and religious histories from birth until the survey. It was designed to record standard data on events (dates, places, type of events) but also to pick up information on family control over individual events (people involved in decisions, marriage procedures, etc.).

Several secondary operations are associated with these two major surveys. For instance, the repeat survey includes various modules on domestic groups, concerning their structure (kinship charts), economic organization (the resources survey), and dynamics (the segmentation module). The life event history survey, for its part, involves collection of genealogical data and dating references (lineage calendars) based on parish data and civil records. Lastly, one-off quantitative and qualitative surveys on specific questions are regularly carried out; for instance, on adolescent migration or on the family environment and gendered relationships at different ages.

\footnotetext{
${ }^{11}$ For a more detailed description of the data collection system, see Hertrich 1996.
} 


\subsection{Several surveys but a common feature: The same questions repeated at each visit}

The two surveys are based on the same principle: a repeat visit to the same populations once every five years, with similar questionnaires from one visit to the next, in order to update the databases and monitor the population. The practicalities, however, are very different for each survey.

The main purpose of the repeat survey is to ask questions about individuals who have entered or left the observation area, and there are no particular questions for people who were present from one survey to the next. The aim is to find out about the residential status, location, and situation at each census of each individual recorded in any one of them. The data collection strategy consists in gathering lineage members together to work in a group. The discussion provides a means to compare and complement the knowledge of each individual, to clarify statements where required, and limit non-response. It is an entertaining exercise, a game of 'happy families' of sorts, in which the villagers willingly take part and which they generally do not view as tedious. In this way we have obtained excellent coverage, and only three out of 2,335 individuals registered in the 1976 census could not be identified during our first visit in 1988. Later sample attrition was also minor, and in only a few exceptional cases have we been unable to identify individuals or learn what has become of them. Most refusals are attributable to one village that withdrew from the repeat survey in 1999; a few families in two others villages also stayed away from the project after the first or second visit, but such occurrences did not increase over time. In both cases, the refusals were not due to boredom with the survey but stemmed from the negative attitude of certain groups or individuals to our project, or more generally to the collective projects in their village. $^{12}$

In the life event history survey, the questions are more personal and the interview is much longer, often more than two hours. In the case of adults, the initial survey took the form of a private interview in our hut in the village. This was time-consuming (organizing meetings and reminders), but provided a good setting for the interviews in terms of confidentiality, availability, and consent (the respondents freed up their time to come), as well as quality of contact. We followed the same procedure during later waves of the survey when we recorded the complete life event histories of the new residents (new wives from other villages, migrants who returned to the village, etc.) and updated the histories of individuals who had experienced major events (such as

\footnotetext{
${ }^{12}$ Those who refused were often families or individuals who were in dispute with community structures or wanted to maintain a certain distance (internal conflict within the village, refusal to take part in collective village projects and events, etc.). A negative attitude to the survey provided them with an additional means to demonstrate their 'non-alignment'.
} 
marriage or repeat migration) since our last visit. The straightforward event history updates are carried out by simply visiting the families. Information about migrants and children is collected from their closest relatives. Only two individuals refused to take part in the initial life event history survey. There may have been more refusals during the later visits that were not necessarily expressed as such, since repeated absences or missed meetings could signify disguised refusal by avoidance. However, the proportion was always very low (never more than $5 \%$ of the total). Some cases of refusal or avoidance may have concerned people who had been interviewed during previous visits and who were tired of the repeated questioning, but more often they were newcomers, notably young wives, worried about the personal nature of the questions that might be asked. Even though the proportion was very low, the refusals do raise the question of how to explain and justify a scientific survey which is of no visible on-the-spot benefit to the target population.

\subsection{Organization in the field}

In this research project, data are collected directly by the researchers working on the survey data. The original surveys were carried out entirely by the project leader during several long field trips in 1987-89. The five-yearly updates usually take place over a two-year period (in two dry seasons) and are conducted with between one and three demography students. As the same persons conduct the various survey waves they acquire extensive knowledge of the different aspects of the project and ensure consistency between the different types of data. In addition, the continued presence of the project leaders over time and their involvement in the field work has led to the development of regular personal relationships with the population, which we believe also contributes to data quality. If we include the additional field trips external to the updating process (interview campaigns, preparatory trips, etc.), scarcely a two-year period has ever elapsed without a presence in the field.

The survey data are collected with the help of local interpreters; usually people who live close to the study villages and who know the local dialect in addition to oral French. While French is the country's official language, it is not spoken in the target villages, so the interviews are carried out in the Bwa language (Boré).

The entire team (researchers/interviewers and interpreters) lives on the spot for the duration of the survey, in the two villages involved in the life event history survey. The village heads place a mud hut (often belonging to an emigrant) at our disposal. This serves as accommodation for the team as well as a venue for the interviews. A woman from the village prepares meals and carries out other domestic tasks. We travel by motorcycle from our 'pied-à-terre' to the other villages in the survey. 
The data collection conditions are quite different from those of a standard largescale demographic survey where fieldwork is carried out by interviewers trained by the researchers. Here, the respondents are in direct and regular contact with the research team and project leader during survey implementation, and also informally during leisure time in the village.

\section{First stage: Obtaining the agreement of the population, a necessary formality}

Before launching any survey, we obtain the agreement of the population's representatives, and this procedure is repeated before every visit. Even after longstanding exchanges with the village with no reason to fear any reticence on the part of the villagers, the formal procedures to inform and validate the survey organization with the parties concerned is an important stage, as it provides a firm grounding for subsequent dialogue and for the consent of the target population.

In practical terms, this involves requesting that a public meeting be organized in each of the villages concerned by the survey, during which the project is described and people can raise their questions. This allows us to highlight the scientific status of the survey, a very important point for avoiding misunderstandings about the survey's purpose, especially in a context where any western presence is closely associated with NGOs. We emphasize and repeat publicly that the survey is not related to any development project and try to forestall any expectations that might arise from such a misunderstanding (Hertrich, forthcoming).

The public presentation of the project (its objectives, the team, practical organization, etc.) and its acceptance by the village community lend visibility and legitimacy to the survey. By officially agreeing to receive us and take part in the project, the village representatives define our status and give us a right to circulate and to establish personalized contacts in the village, freeing us from the protocol that usually governs the movements of 'strangers' in the village.

Such meetings requiring the formal agreement of the villagers are the prerequisite for any new data collection phase. Two meetings are usually organized in each village. The first is held a few months before the survey and is really a request on our part to be invited into the village. The second confirms the villagers' acceptance and allows us to describe and launch the data collection operation. These rather formal meetings are organized and led by the village heads, but they are more than mere formalities. For instance, one village that had expressed misgivings during a first contact later joined the survey after debating the matter internally. Conversely, survey participation was stopped in one village in 1999 when the villagers decided that they no longer wanted to 
take part without any material compensation. These exchanges and the stances adopted cast a new light on the notion of 'vulnerability', often dominant in scientific discourse, notably in the debate on ethics, when dealing with populations that do not correspond to socioeconomic norms. In our case, we do not believe that the population's 'poverty' and low educational level have ever lessened their demands for information and decisionmaking autonomy in the villages where we work. ${ }^{13}$

\section{Highlighting the population's contribution to the survey: Basic feedback methods}

From the very start of the survey we wanted to provide a practical expression of the importance of the survey and our appreciation of the population's participation. There were several reasons for this: first, to confer visibility and reality to what might seem a very abstract approach; second, to differentiate our approach from that of the NGOs; and, last, to encourage the population to support the project through recognition of its role in our research.

Until 2003, we informed villagers about the survey in three different ways:

1) By handing out documents from the survey, collectively and individually. From the start, we handed out copies of theses and books relating to the survey to each of the villages concerned. We also gave individualized data to the two villages involved in the life event history survey. Each lineage representative received his patrilineal family tree and every adult received the event history sheet listing the main individual events (marriages, births, and migrations) concerning him or her. An updated version of the event history sheet is provided every five years. Although this form of feedback may seem inappropriate for an illiterate population, these documents are carefully stored by the villagers as evidence of their participation in the survey, and, more importantly, as a mark of prestige and a souvenir for themselves and for their families. In 1988 when we worked with the lineage elders on tracing their ancestry, some of them told us that this approach was important to them and viewed it as a medium for transmitting family history - something that has become more difficult in a time of urban migration when the consumer society is distancing the younger generations from the tales of their elders. Now that those young men have in turn become fathers and the holders of their family histories, they have expressed gratitude to us for recording the information before it disappeared with their fathers. The value placed on the life event history sheet is of a different, more personal nature. As it is provided to each adult, whatever their

\footnotetext{
${ }^{13}$ This strong desire for autonomy, also reported for other populations of the region (the Dogon, for example) is manifested in many other ways, notably via their relationships with the dominant institutions (Islam, public structures, etc.) (Diarra 2007; Hertrich 1996).
} 
gender and rank in the family and social structures, the life-event history sheet is considered a mark of respect and personal recognition, independently of sex and age. Our experience thus suggests that the use of conventional paper documents should not be rejected out of hand, even in a population largely unfamiliar with the written word. Such documents are easy to produce after a survey, and they provide a tangible dimension to the research and feedback project while providing physical evidence of the value of the testimonies received and of their contribution to the histories of the families surveyed.

2) By featuring the survey in the local media. Our research received local media coverage on several occasions: local radio broadcasts, an article in the diocesan review, a conference in Bamako advertised on the national radio, and, especially in 2003-2004, various reports on national radio and TV covering the demography seminar (see below) and the resulting book. These were all in French and did not seek to address the survey populations themselves: while local radio has attracted a large audience since its creation in the mid 1990s, televisions are a novelty in the villages. The villagers nonetheless found out about these programmes when visiting a neighbouring town or when they heard the name of their village mentioned on the air.

This media coverage helped us indirectly because it placed the spotlight on the villages concerned. The value the Bwa place on reputation is clear from their good wishes and greetings, which are built around this notion. By making the villagers 'famous', the survey has a symbolic impact, perceived as a positive spin-off by the villagers. It strengthens their commitment to the project and boosts their pride.

3) Finally, taking part in village life allows us to express our gratitude in different ways. Celebrations are very important for the Bwa people and provide us with a way of expressing our thanks to the population as a whole. We have organized several celebrations in the two villages where we stay, and have contributed to organizing them in others, for instance by paying for a griot band or buying millet beer. In 2003 we organized an exceptional aid donation during a food shortage that arose because of drought in the previous agricultural season. Lastly, marks of respect at important family and social events, such as funerals, weddings, and village celebrations, even longdistance ones, with messages transmitted over the local radio at the beginning of the farming season and at the year end or in letters, are an integral part of the relational aspect of such a long-term project.

These three basic ways of highlighting the value of people's participation in our research have been part and parcel of our survey routine up to now, but further action is necessary to ensure full and effective feedback. 


\section{The concept of a specific feedback project}

The year 2003 marked a turning point in our approach. We deliberately decided to focus our activities on scientific communication, especially in terms of post-survey dissemination to respondents.

The decision was made for ethical, scientific, and practical reasons. From the ethical point of view, we were dissatisfied with our approach to the population. For one thing, neither the types of feedback (documents, village meetings, etc.), or their content were really designed for the villagers, and therefore were not readily 'understandable' by that type of audience. For another, to avoid confusion between our research status and that of the development NGOs, it was important to make our research visible to the population in truly practical terms (Hertrich, forthcoming). We had been mulling over a specially designed feedback project for several years without having reached the implementation stage. It was time to recognize that such an operation had little chance of taking shape if we did not treat it as a project in itself, and a priority project at that. Lastly, from a scientific point of view, the withdrawal of one village during a previous field trip, as well as some reticence that we had heard about here and there, were signs of misgivings among the population. To clarify the status of the survey and the team, and to make the survey intelligible and therefore something that could be discussed in full knowledge of the subject, it was time to design a form of dissemination that would very clearly show the results of the research to a broad section of the survey population, and not just a few of its representatives.

At local level our strategy was two-fold: an audiovisual presentation in the local language and theatre sketches by the villagers on the subjects of the survey. This was implemented for the first time in 2003, and then again in 2009.

We should add that the 2003 programme included a national dimension in the form of a scientific seminar on population issues in Mali ${ }^{14}$, organized with our Mali institutional partners. Although it did not focus on our research as such, it did tie in with

\footnotetext{
${ }^{14}$ The project was a partnership between INED together with the Centre national de la recherche scientifique et technologique (CNRST, Bamako), the Centre d'études et de recherche sur la population et le développement (CERPOD-INSAH, Bamako), the Direction nationale de la statistique et de l'informatique (DNSI, Bamako) and the University of Bamako (ENSUP - FLASH), and received funding from the Fonds de coopération et d'action culturelle of the French Embassy to Mali and from the United Nations Population Fund in Mali (UNFPA, Bamako).

The seminar brought together a dozen speakers (researchers, statisticians, and academics) from Mali and France. The aim was to present demographic issues and promote awareness to a broad audience of Malian intellectuals: decision-makers, institutions, field workers, academics, journalists, etc. To reach the broadest possible audience the event was repeated on three occasions on 6, 7, and 9 January 2003, at the University of Bamako, the French Cultural Centre in Bamako, and a conference centre in the town of San, close to the survey area. It was followed by a book (Hertrich and Keïta 2003), widely distributed in Mali for a symbolic price, thanks to the support of the UNFPA, and it is still available free of charge in PDF format on the website (http://questions_population_mali.site.ined.fr/).
} 
our local feedback project, because the media interest in the seminar was a factor of local pride, and representatives from each of the villages were invited to take part at one of the seminars (the one held in the nearest town). Thus, in a way, the villages saw themselves as being a party to these events.

\section{The audio-visual presentation: Objectives and implementation}

Because of its advantages, the audiovisual medium stood out immediately as the ideal tool for our feedback project. It enables us to move away from the formal written, academic document and provide an entertaining and attractive means of communicating, while disseminating information to a large and varied audience of all ages. It also gives considerable freedom in design and implementation, as well as in the type of language used. However, we were entering a domain that was a long way from our traditional scientific practice in terms of both skills and budget. The production costs for making a film would have far exceeded the budget of the research project it was supposed to explain. Since using professional services was beyond our means, we decided to devise our own feedback project using available audiovisual and computing tools. Our final product was a half-hour animated film in the local language, produced with PowerPoint software (Lesclingand and Hertrich 2007). The presentation is available on the website of Demographic Research for download as either English $[100 \mathrm{MB}]$ or French [100MB] version (After downloading the zip-file, extract files to your local hard disc, then run "show.pps". If the files are not extracted to your computer, the soundtrack will not run).

This audio-visual project was constructed around a basic objective: to share the results and concerns of our research project with the villages and the villagers who had taken part over many years. We had two imperatives: to be interesting and to be understood. These guidelines led to our choice of content and method of organizing the information.

\subsection{Capturing viewers' interest: Which ideas should take priority?}

We did not aim to select any particular topic; for example, by asking the villagers what ideas they wanted to explore, as we thought it important to address all the various themes of our project. However, we drew largely on the experience gained through our repeated presence in the villages and our daily exchanges with the population to develop and personalize our presentation, in line with what we knew about villagers' concerns and areas of interest. We decided to focus on three messages: 
- The demographic and social changes in the villages. Since these issues are at the heart of our research and scientific publications, they had also to be included in the feedback project and, in fact, most of the presentation was devoted to them. After listing the various issues, we re-worked and reformulated them to tie in with the villagers' own concerns. The representations and perceptions of past and present developments were systematically introduced as a lead-in or focus of discussion about the survey results. The slide show therefore placed the survey in a perspective that shed more factual light on certain idealistic positions (for instance, "were the large families in the old days really quite so large?") or simplistic viewpoints on the changes under way (such as, "has marriage really become an individual matter?")

- A comparative national and international perspective was included in response to the curiosity expressed indirectly by villagers during our informal gatherings through their questions on the situation abroad. We wanted to put our research into a perspective that would provide them with a framework and reference to the world and their position in it, but we also wanted to broach the developments and tensions currently experienced by the communities from a relative standpoint. Thus, descriptions of mortality and fertility trends during demographic transition enabled us to include the villages' experience in a shared, collective history. For instance, by showing that many communities have experienced pressure on land during demographic transition, we were able to play down the trend and put the share of human responsibility into perspective (e.g., land pressure is related to population growth, not poor land management by the village heads).

- The importance of the survey process and the villagers' contribution was the third message included in the slideshow. The multi-round survey system that entails asking the villagers the same questions every five years is a cumbersome process and depends on the participation and allegiance of all the villagers. We wanted to express our recognition of this individual and collective commitment and show the villagers that they are our partners in this research project. We tried to do this in two ways: by devoting the first part of the presentation to the data collection process and how it is carried out in the community, and by including photographs of the villagers throughout the presentation.

With these goals in mind, we produced a 66-slide synopsis in 9 parts: the presentation of the villages and the team, the objectives of the research project and the data collection methods, changes in mortality, changes in fertility, population growth, changes in family structure, changes in migration, changes in marriage, and local development projects. 


\subsection{Making ourselves understood: How should the process be formalized?}

The main challenge we faced in preparing our presentation was to find appropriate forms of expression and representation for the content of our message and the sensibilities of our audience. We dealt with this by making some decisions at the outset about which forms of expression should take preference, and which should be avoided. Generally speaking, we tried to avoid using graphs or written words and figures. If a number is mentioned on a slide, it simply provides additional information and is not needed to make the slide understandable (for example the number of people in the village, Figure 1b). We also avoided any references to calendar years or units of measurement not used by the local communities. In general we used orders of magnitude, and comparisons of quantities were visualized by different sizes or numbers of representative images (Figure 1a). Notions of risk and comparisons of behaviour between generations were depicted by animations of ten individuals reacting in various ways in response to a given event (Figure 1c). We represented dates and the passage of time in two ways, by using events known as period indicators, such as independence in the early 1960s or the great drought in the 1970s, and by using photographs of villagers belonging to the cohorts we were referring to. Figure 1 shows a few examples of the slides we used in our presentation.

\subsection{Images and language}

Since the photographs we used were mostly of the villages, the slide show was anything but anonymous. We needed to convey the idea that the survey 'belonged' to the respondents, so logically they had to play the leading role. We used many pictures of them to support what we were saying, whether to show the age of the cohorts we were discussing, or to identify the villages by showing photographs of their representatives (administrative head, land master, and women's representative) (Figure 1b). We also tried to get as close as possible to the population's own mode of communication when preparing the spoken commentary. It was written in French, then translated and recorded in the local language, and we used the images, vocabulary, and certain sentence constructions that we had learnt during our long presence in the field. This was not only to guide the translator but also to show that we wanted to stick to the local form of expression from the start. Lastly, we included background music to give a festive touch to the presentation. 
Figure 1: Pictures from the slide show
a. The growth of the villages (shown by the increase in the number of houses)

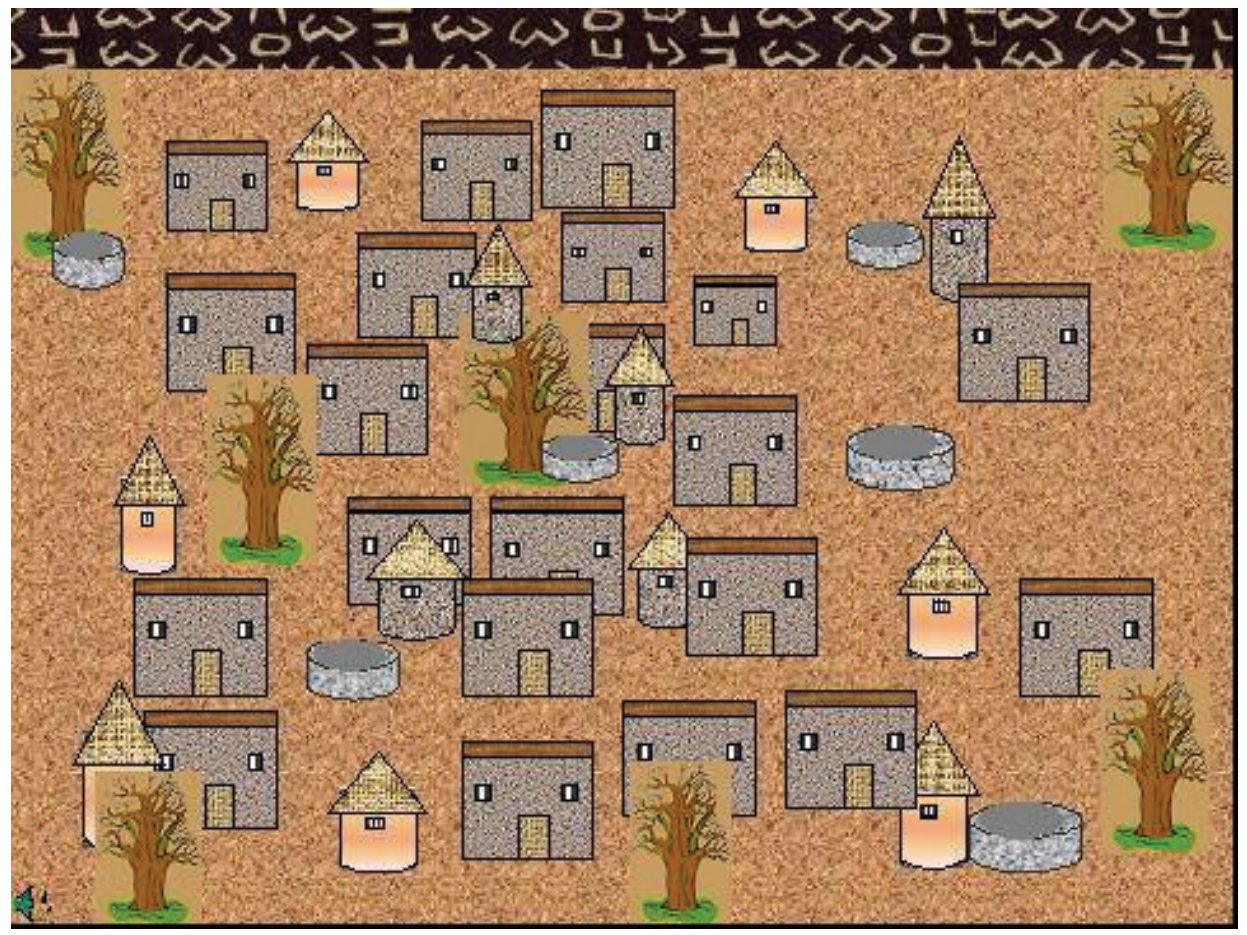

Spoken commentary:

"Children who are born and people who come to live in the village both increase the size of the village."

"But two things can decrease the population. People who die and people who move out of the village to go and live in another village or in the city." 
Figure 1: (Continued)

b. Picture used to show the village population increase between the first and the most recent census
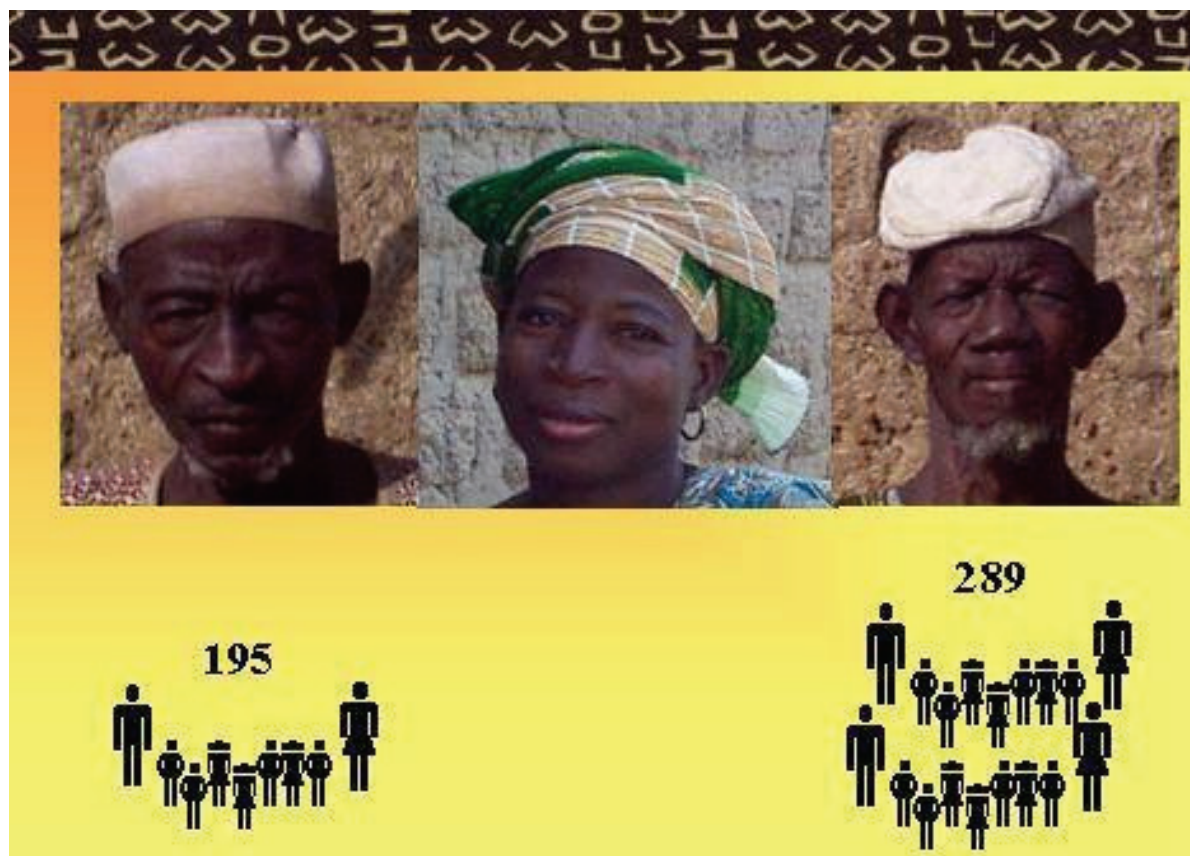

(19)

Note: The photos are of the various heads (administrative head, tribal chief, women's representative) of the village concerned.

Spoken commentary: "The time of the great drought, about 200 people were living in the village, now there are about $300 . "$ 
Figure 1: (Continued)

\section{c. Picture used to explain changes in infant mortality}

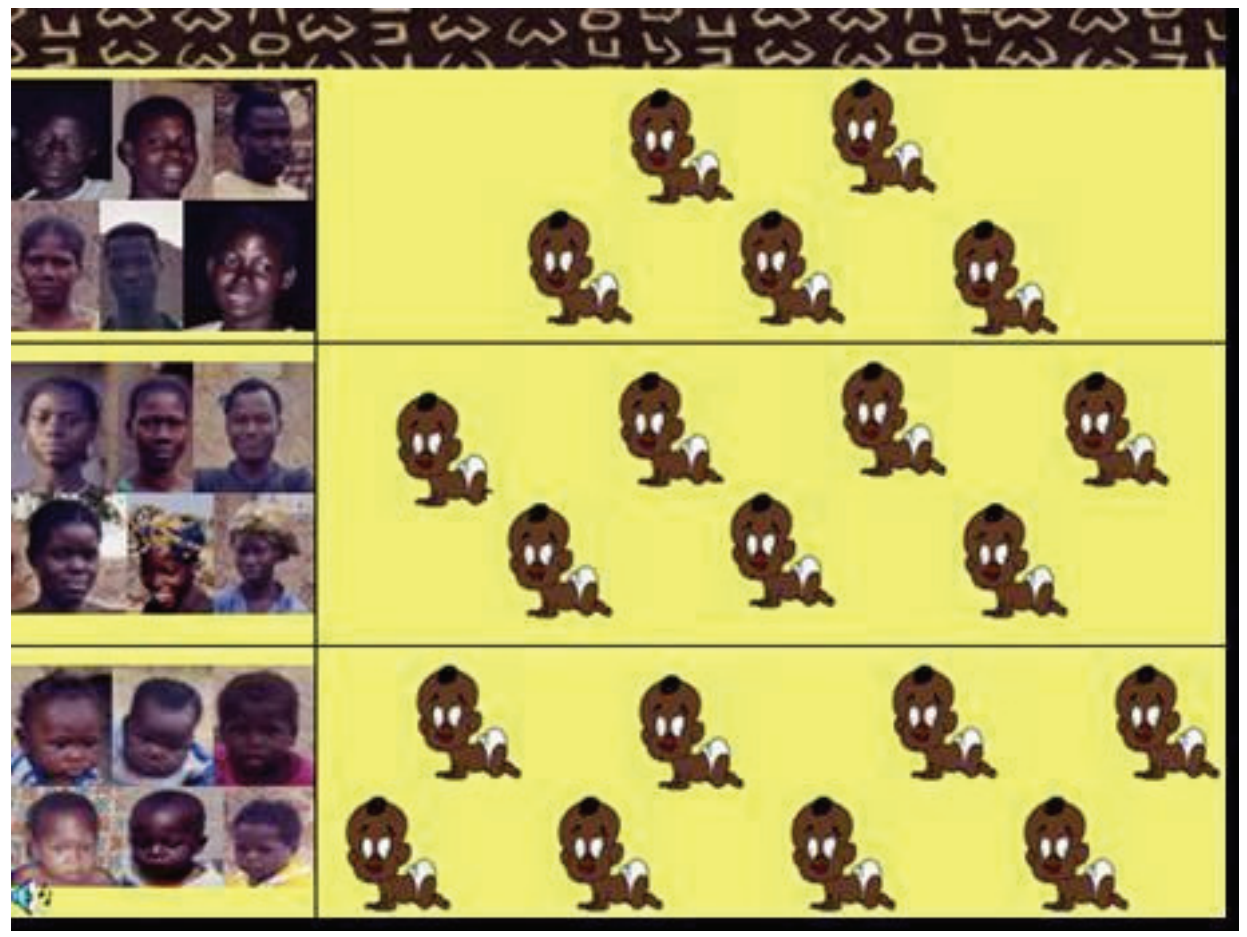

Note: The photos (of villagers) indicate the generations, while the number of babies represents the number of children surviving at age 5 years for every 10 births.

Spoken commentary (over 4 slides):

[1st slide] "If we look at people who were born around the time of independence, like these people, out of 10 children born, 5 died before they had lived for 5 rainy seasons."

[2nd slide] "Let's look now at those who were born around the time of the great drought, out of 10 children born, 3 died before they had lived for 5 rainy seasons."

[3d slide] "Among small children born today, out of 10 children, only 2 die before they are 5 ."

[4th slide - summarising the previous ones] "Mortality has therefore decreased over the last 50 years." 


\section{Sketches in a village show}

When we decided to organize a communication campaign for the population, we realized that it would be far more effective if the exchange were mutual. We needed to find an attractive format in which to address the villagers, but we also wanted them to communicate and propose their representations of our subjects. So we suggested that they prepare some sketches dealing with some of the subjects in the survey, such as migration, marriage, and relationships between spouses.

This idea emerged quite spontaneously when we were thinking about ways in which the villagers could communicate. Theatre sketches are often used for awareness campaigns in the country, but they are also popular forms of entertainment during the festivals put on by local organizations. Even though the villagers had no theatrical experience as such, we thought that it was an entertaining form of expression that they were likely to enjoy (Stuttaford et al. 2006).

The population's response exceeded our expectations. Each village came up with one or two elaborate playlets lasting between 15-30 minutes, involving between five and ten 'actors' and an elaborate set with props and costumes. The sketches were usually performed by groups of young adults (either both sexes or only men) but sometimes also by older adults. To give them ideas for sketches, we drew up a list of a dozen themes that lent themselves well to parody while sticking to the subjects broached in our survey. It provided a variety of suggestions that the villagers could use for inspiration. The list served to encourage initiatives (give ideas) rather than to structure the villager's sketches. The subjects they selected (about half of our suggestions plus several sketches based on other scenarios) all had considerable comic potential, either in the subject itself or the way it could be staged. Thus, in 2003, the subject of young men's migration with its misadventures (searching for jobs, employer abuse, the shame of returning to the village with no money) was the most popular theme, used for 7 out of 12 sketches. In 2009, the sketch most often performed showed the decisions made by a family head faced with the illness of one of his children (medical expenses) and the others' expectations of the approaching Christmas festivities. Once again, the extreme positions present in the dilemma make room for caricature and promised good comic potential.

A list of subjects used in the villagers' sketches is given in Box 1 below.

The video of one sketch, with English (high quality [318MB], low quality [118MB]) and French (high quality [318MB], low quality [118MB]) subtitles, is available on the website of Demographic Research, attached to this article. It concerns the topic of young girls who migrate to the city to work as maids. All the parts are played by young men, including the female roles. 


\section{Box 1: $\quad$ Subjects of sketches played by the villagers $(2003,2009)$}

Migration
- A young girl sees her friends return from the city. She wants to go there too but her parents
refuse. She leaves in secret.
- A young man returns from the city without having earned any money.
found him a wife, but nothing has been done.
Marriage
- A young girl has just learnt that her parents have agreed to her marriage. Nobody has told
her and she does not agree.
The same situation for a young man for whom a wife has been found.
Relations between spouses and family life
A woman has heard about medicines that stop you getting pregnant. She already has
several children and would like to wait before having more. She discusses this with her
husband.
A woman sees that her husband is selling a great deal of grain in order to drink millet beer.
She is afraid that there will not be enough to last until the next rainy season. She tells her
husband that he is irresponsible.
A man wants to leave his father and start farming alone. He wants his own land, and goes
to see his father.
Christmas is coming. A family has sold a goat. For the past two days one of the youngest
children is feverish and his mother is worried. What should the parents do with the goat
money, take the child to the dispensary or buy what they need for Christmas?

\section{Communication, 'theatre' and 'cinema': Dissemination through spectacle?}

The audiovisual presentation and the village sketches were presented at the same time, with a specific time set aside for both events in each of the villages. We arranged for the entertainment to take place at the end of the day, with the first part of the show devoted to the theatre sketches and the second part, after nightfall, to our presentation of survey results. We decided to film the village sketches so that we could keep a record of them and project them again at a later date. We removed our research hat for a time and transformed ourselves into a mobile cinema unit, complete with electricity generator, video projector, laptop, and video camera. 
The villagers clearly perceived the two events as evening entertainment and they came in large numbers to see the sketches, and especially for the audiovisual projection presented in 2003. By projecting the slide show at night we drew people when they were free from their routine activities, especially the women who are taken up by domestic tasks and are rarely present at public meetings. At each venue the event took place in a public square using the outside wall of a house for a screen, occasionally covered by a sheet. A big-screen projection in the local language is a rare event in the villages and most people had never seen such a thing. Seeing photos of people known to them (inhabitants of their village and neighbouring ones) helped to capture the public's attention and emotions. One showing was rarely enough to satisfy the villagers and sometimes we had to project the presentation several times in succession.

This first experiment was followed by another in 2004, when we began a new data-gathering operation. This time we projected the sketches we had filmed a year earlier, along with a personalized slide show of the photographs taken in the village over the past 15 years.

In 2009, on the occasion of a new survey round, we used the 'theatre and cinema' formula again, with some new adjustments. The audiovisual presentation changed in two respects: the results were updated, and a part detailing the data collection process was added. This provided a kind of introduction to the new phase of the survey by explaining the approach and the issues involved and pointing out the new questions in the questionnaires. ${ }^{15}$

\section{Assessment and lessons learnt}

\subsection{Satisfied villagers and satisfied researchers}

For several reasons we believe that the experiment was a success. For one thing, the mobilization of the villagers showed that the project made sense to them. First, their involvement in creating the sketches and sets, second the large and varied audience (both sexes and all ages) at the slide show in each of the venues, and finally their requests for repeat projections, show that it was not perceived as an artificial exercise, disconnected from local reality. Furthermore, the villagers explicitly showed their pleasure and gratitude at the end of the projection (applause and compliments) and in the days that followed. Lastly, the warm welcome received by the 2004 survey and the comments we heard here and there ("now we understand what it's for") have convinced

\footnotetext{
${ }^{15}$ However, exceptionally low temperatures in the region affected the impact of this new presentation, which took place in January 2009. The villagers were reluctant to go out in the cold, so far fewer attended the projection than in 2003.
} 
us that the dissemination project contributed to villagers' awareness of the research issues and renewed their confidence in the survey. But while the audience was smaller in 2009, there were far more individual requests for explanations during the 2009-2010 survey. Finally, the population now considers the audiovisual show as part and parcel of the survey process, and it would probably be difficult to justify its cancellation.

\subsection{Public debate and knowledge transmission}

For the persons concerned, what was the point of this knowledge dissemination operation? To what extent was there really a transmission of knowledge? We can only provide a qualified answer to these questions. When we devised the project our aim was to communicate information, and we viewed the formalization process as a vehicle for transmission of content to a wide audience. We therefore expected the villagers to react to the messages contained in our slide show; for instance through debate, discussion, and questions. In fact, while they expressed pleasure at seeing the slide show, the villagers never really expressed their views on the content. This does not mean that they did not understand the information, or that they accepted it without thinking, but rather that the event was seen as a form of 'entertainment'. In a context where audiovisual media are still rare, watching a show on a big screen and seeing photos of known people is an exciting event in itself. To retain the information that was provided and assess it objectively would suppose that prior thought was given to the subject, or, in other words, that the villagers put aside their spectator roles to become actors in the issues that were broached. With hindsight, this point of view seems quite naïve. Why should people be expected to devote time and thought to the concerns of researchers?

We did not carry out an ex-post assessment to analyse what information the villagers may have retained from our operation. But it does seem important to recognize that an inevitable gap exists between what researchers can provide and what the population expects (Olivier de Sardan 1990). There is no reason to think that the two will correspond (Hertrich, forthcoming). This in no way detracts from the relevance and ethical need for a feedback operation, but we do need to recognize that the people concerned are free to absorb the information they receive in any way they like.

Lastly, the feedback process should take account of developments in relationships with the population over time. Feedback provided at a given time can contribute to longer-term considerations and expectations. For instance, recently, in 2009-2010, we received new requests from the village heads for access to the survey results, notably data concerning the population size and structure that could be used to support local development projects. As elsewhere (Madhavan et al. 2007), the combination of decentralization and local development programmes is boosting the 'availability' of 
existing data and contributing to the emergence of an explicit demand for results that can serve the village's own projects.

\subsection{Creating a shared space around the survey}

A dissemination project brings together different types of social actors, and may be expected to meet a wide range of expectations. From this point of view, one vital contribution of a repeated feedback operation is its role in creating and nurturing a shared space, where people can express themselves if they want to. Indeed, the feedback project opens a space for discussion and a time for exchanges on a level different from that of the survey itself. This time is not devoted to data collection and is therefore seen as free disinterested time for dialogue between the researchers and the population. This collective space can also be used as a medium for constructing and expressing the team's shared history with the population and for highlighting a shared culture. In addition to the research findings, other topics and other media can enter this common arena, without necessarily being associated with new outputs. For instance, between two dissemination operations we projected in each village the sketches we had filmed during a previous visit and some personalized photo slide shows. Various other possibilities could be explored to disseminate information and entertainment, including events involving several villages - for instance performing sketches in one village that were prepared in another - or inviting outside participants.

It is important to develop and nurture this shared space over time, while understanding that it may be occupied in a variety of ways and fed by a range of events. The questions, expectations, and players may change over time, but in setting aside this shared space and time we provide a framework in which, when the time comes, people can express themselves and elicit answers from the research team. Perhaps the researcher's ethical responsibility is first and foremost to ensure that this shared space is created and maintained over time, while accepting that it may be used in a variety of different ways. 


\section{Acknowledgements}

First, we wish to express our gratitude to the villagers for taking part in our research over so many years, and for devoting so much time and energy to the survey and to the many sketches they have produced. Their friendly welcome and the opportunities for dialogue thus created have provided fertile ground for a reflexive approach to our work, encouraging us to move away from standard research formats in terms of concepts, data collection, and research questions, but also in terms of communication and feedback. We also wish to thank the interpreters, who play a vital role both in the survey itself and in the formal and informal exchanges with villagers.

We also received invaluable assistance from several people to organize the feedback initiatives and prepare the audiovisual material accompanying this article. Our warm thanks to Honoré Dackouo, Aurélien Dasré, Alexis Dembelé, Pierre Diarra and especially Abednego Kamaté, who has been at our side for more than 20 years now.

Our thanks also to our colleagues - Nathalie Mondain, Jacques Vallin and Gilles Pison in particular - for their comments on an earlier version of this article.

This article has been translated from French by Catriona Dutreuilh and Krystyna Horko. 


\section{References}

Bergier, B. (2000). Repères pour une restitution des résultats de la recherche en sciences sociales. Paris: L’Harmattan.

Bizeul, D. (2008). Les sociologues ont-ils des comptes à rendre? Enquêter et publier sur le Front national. Sociétés contemporaines 70: 95-113.

Bonnet, D. (ed.) (2003). L'éthique médicale dans les pays en développement. Autrepart 28 (Special Issue).

Bosa, B. (2008). À l'épreuve des comités d'éthique. Des codes aux pratiques. In: Fassin, D. and Bensa, A. (eds.). Les politiques de l'enquête. Épreuves ethnographiques. Paris: La Découverte: 205-225.

Capron, J. (1973). Communautés villageoises bwa. Mali-Haute Volta. Paris: Museum National d'Histoire Naturelle. (Mémoires de l'Institut d'ethnologie, IX, Tome I, fasc. 1).

Capron, J. (1988). Introduction à l'étude d'une société villageoise. 1955-1968. Tours: Université François-Rabelais de Tours. (Mémoire du Laboratoire d'anthropologie et de sociologie $\left.n^{\circ} \mathrm{II}\right)$.

Diarra, J.T. (2007). États, Églises et sociétés. Les Buwa, les mécanismes oubliés d'une marginalisation. Bamako: Edim-sa.

Fassin, D. (2008). Répondre de sa recherche. L'anthropologue face à ses 'autres'. In: Fassin, D. and Bensa, A. (eds.). Les politiques de l'enquête. Épreuves ethnographiques. Paris: La Découverte: 299-322.

Fassin, D. and Bensa, A. (eds.) (2008). Les politiques de l'enquête. Épreuves ethnographiques. Paris: La Découverte.

Flamand, N. (2005). Observer, analyser, restituer. Conditions et contradictions de l'enquête ethnologique en entreprise. Terrain 44: 137-152.

Hertrich, V. (1996). Permanences et changements de l'Afrique rurale: dynamiques familiales chez les Bwa du Mali. Paris: Ceped (Les Études du Ceped $\left.n^{\circ} 14\right)$. http://ceped.org/cdrom/integral_publication_1988_2002/etudes/pdf/etudes_cpd_ 14.pdf. 
Hertrich, V. (forthcoming). Entre les attentes des enquêtés et la dette du chercheur, réflexions autour d'une démarche de restitution au Mali. Interrogations? 13.

Hertrich, V. and Keïta, S. (eds.) (2003). Questions de population au Mali. Bamako: Le Figuier, UNFPA-Mali. http://questions_population_mali.site.ined.fr/.

Kobelinsky, C. (2008). Les situations de retour. Restituer sa recherche à ses enquêtés. In: Fassin, D. and Bensa, A. (eds.). Les politiques de l'enquête. Épreuves ethnographiques. Paris: La Découverte: 185-204.

Lesclingand, M. and Hertrich, V. (2007). Quand la population change. Restitution d'une recherche au Mali [When the population is changing. A presentation of research findings in Mali]. Paris: Ined. (CD with the audio-visual dissemination project).

MacLeod, C.T., Masilela, T.C., and Malomane, E. (1998). Feedback of research results: Reflections from a community-based Mental Health Program. South African Journal of Psychology 28(4): 215-221.

Madhavan, S., Collinson, M., Townsend, N.W., Kahn, K., and Tollman, S.M. (2007). The implications of long term community involvement for the production and circulation of population knowledge. Demographic Research 17(13): 369-388. http://www.demographic-research.org/volumes/vol17/13/. doi:10.4054/DemRes. 2007.17.13.

Mondain, N. and Bologo, E.A. (2009). L'intentionnalité du chercheur dans ses pratiques de production de connaissances: les enjeux soulevés par la construction des données en démographie et santé en Afrique. Cahiers de recherche sociologique 48: 175-218.

Mondain, N., Bologo, E.A., and Arduin, P. (2010). Exploring respondents understanding and perceptions of demographic surveillance systems in Western Africa: Methodological and ethical issues. African Population Studies 24(3): 149-165.

Olivier de Sardan, J.-P. (1990). Sociétés et développement. In: Fassin, D. and Jaffré, Y. (eds.). Sociétés, développement et santé. Paris: Ellipses, Aupelf: 28-37.

Pison, G. (2005). Population observatories as sources of information on mortality in developing countries. Demographic Research 13(13): 301-334. http://www.demographic-research.org/volumes/vol13/13/. doi:10.4054/DemRes. 2005.13.13. 
Stuttaford, M., Bryanston, C., Hundt, G.L., Connor, M., Thorogood, M., and Tollman, S. (2006). Use of applied theatre in health research dissemination and data validation: A pilot study from South Africa. Health 10(1): 31-45. http://hea.sagepub.com/content/10/1/31. doi:10.1177/1363459306058985.

Zonabend, F. (1994). De l'objet et de sa restitution en anthropologie. Gradhiva 16: 314. 
Hertrich et al:: Constructing a survey over time: Audio-visual feedback and theatre sketches in rural Mali 